\title{
Pharmaceutical actuation in intensive care units: contributions to rational use of drugs
}

\begin{abstract}
Objective: Evaluate the performance of the clinical pharmacist in Adult Intensive Care Units of a special-sized hospital, wherein pharmacotherapeutic follow-up is the main activity developed by the pharmacist residing in intensive care. Methods: This is an observational, cross-sectional study with a quantitative approach, carried out in Adult Intensive Care Units, from March to June 2018. Data were collected from the Clinical Pharmacy Service, by means of already established indicators. Results: During the study period, 958 patients were admitted and 664 were included in the study. Regarding the place of hospitalization, $57 \%$ of the patients included in the study were hospitalized in the Post-operative Intensive Care Unit and 43\% in the Clinical Intensive Care Unit. The suggested interventions were well accepted (99.6\%), and in the clinical intensive care unit, the number of interventions performed and the cost saving were higher in all months of the study. The main interventions were drugs inclusion / withdrawal, dose reduction, infusion time and dilution. Of the interventions accepted, 25\% generated cost savings, saving R \$163,656.40 in total, and the types of interventions related to the most frequent cost saving were withdrawal of the drug (58.5\%), dose reduction (32.6\%) and change of pharmaceutical formula (3.0\%). Conclusion: The performance of the clinical pharmacist in intensive care units was well accepted by the medical team. The various possibilities of interventions contribute to rational use of drugs and, in addition, some of these pharmaceutical interventions have a direct impact on cost savings.
\end{abstract}

Keywords: Pharmacy Service, Hospital. Intensive Care Units. Drug Utilization. Cost savings.

\section{Atuação farmacêutica em un idades de terapia intensiva: contribuições para uso racional de medicamentos}

\section{Resumo}

Objetivo: Avaliar a atuação do farmacêutico clínico em Unidades de Terapia Intensiva adulto de um hospital de porte especial, em que, o acompanhamento farmacoterapêutico é a principal atividade desenvolvida pelo farmacêutico residente em terapia intensiva. Métodos: Trata-se de um estudo observacional, do tipo transversal, com abordagem quantitativa, realizado nas Unidades de Terapia Intensiva adulto, no período de março a junho de 2018. Foram coletados dados do Serviço de Farmácia Clínica utilizando indicadores já instituídos. Resultados: No período do estudo, 958 pacientes foram internados e 664 foram incluídos no estudo. Em relação ao local de internação, 57\% dos pacientes incluídos no estudo estavam internados nas Unidades de Terapia Intensiva pósoperatório e 43\% na Unidade De Terapia Intensiva clínica. As intervenções sugeridas foram bem aceitas (99,6\%), sendo que na Unidade de Terapia Intensiva clínica, o número de intervenções realizadas e a redução de custo foram maior em todos os meses do estudo. As principais intervenções realizadas foram inclusão/retirada de medicamentos, redução da dose, tempo de infusão e diluição. Das intervenções aceitas, 25\% geraram redução de custo, economizando $\mathrm{R} \$ 163.656,40$ no total, e os tipos de intervenções relacionadas à redução de custo mais frequentes foram: retirada do medicamento $(58,5 \%)$, redução da dose $(32,6 \%)$ e mudança de fórmula farmacêutica (3,0\%). Conclusão: A atuação do farmacêutico clínico em unidades de terapia intensiva foi bem aceita pela equipe médica. As várias possibilidades de intervenções contribuem para o uso racional de medicamentos e, além disso, algumas dessas intervenções farmacêuticas possuem impacto direto na redução de custos.

Palavras-chave: Serviço de Farmácia Clínica. Unidade de Terapia Intensiva de Adulto. Uso de medicamentos. Redução de custos.
Santa Casa BH Ensino e Pesquisa. Belo Horizonte, MG, Brasil.

Submitted: $17 / 07 / 19$

Resubmitted: $17 / 12 / 19$

Accepted: $31 / 12 / 19$ Blind Reviewers

DOI: $10.30968 /$ rbfhss.2019.104.0429. ISNN: 2316-7750.

Corresponding Author:

Eduarda Cristina Maciel dudacsm@gmail.com 


\section{Introduction}

Medication errors are preventable events that can lead to misuse of medications ${ }^{1 .}$ These errors cause at least one death every day and harm approximately 1.3 million people annually in the United States alone. Globally, medication errors cost about USD 42 billion a year. In response to this worrying picture, the World Health Organization (WHO) launched in 2017 a global initiative to reduce by $50 \%$ serious and preventable drug-related harm in all countries over the next five years. This is the third Global Patient Safety Challenge with the "Harmless Medication" theme ${ }^{2}$.

ICU patients, due to their clinical conditions, polypharmacy, use of potentially hazardous drugs, and a high frequency of changes in pharmacotherapy, have an increased risk of drug-related errors and adverse events, which in turn contribute to a significant increase in length of stay, morbidity and mortality, and increased costs for the institution and the health systems ${ }^{3,4}$. Such errors may occur at any stage of the medication use process, including prescription ${ }^{1}$. Once committed, and not detected, a prescription error will be systematically practiced and may result in significant harm and even death, and is therefore considered the most serious type of medication error ${ }^{5}$.

The pharmaceutical practice in ICUs is regulated by the National Health Surveillance Agency (Agência Nacional de Vigilância Sanitária, ANVISA) through Resolution No. 7 of February 24th, 2010, which requires bedside pharmaceutical care as one of the services that should be guaranteed to the patient, having to be integrated with other care activities provided, being discussed jointly by the multiprofessional team ${ }^{6}$. The incorporation of the clinical pharmacist in the multiprofessional ICU team is effective in reducing risks related to drug use, ensuring pharmaceutical care based on technical and scientific criteria, contributing to patient safety through management mechanisms for effective and rational administration ${ }^{3}$.

The drug therapies have a significant impact on hospital costs ${ }^{7}$. In the study conducted by Weber et al (2003), the ICU drug costs accounted for 38.4\% of the hospital's total drug costs 8 . In this context, the performance of the clinical pharmacist has a positive impact on pharmacoeconomics, since the rational use of drugs provides an effective, safe and low cost treatment, contributing to the integrality of health care, which enables individual and institutional benefits 9 .

There are still scarce Brazilian studies demonstrating the impacts of pharmaceutical interventions on ICUs ${ }^{10-12}$. Given the above, the objective of this study was to evaluate the performance of the clinical pharmacist in adult intensive care units and the contributions to the rational use of drugs.

\section{Methods}

\section{Study design}

Observational and cross-sectional study with a quantitative approach.

\section{Study place}

Hospital characterized by being a Social Assistance Charity, of special size, with 170 ICU beds. The selected ICUs (General Post-operative and Acute Clinical) are composed of 20 beds each, with one pharmacist as a member of the multidisciplinary team every 10 beds.

\section{Study population}

This study included patients followed by the Clinical Pharmacy Service, admitted to the general post-operative (PO) and acute clinical (AC) ICUs, from March to June 2018. The study excluded patients who were not followed up by the Clinical Pharmacy Service and who had no intervention done by the Clinical Pharmacy Service.

\section{Data collection}

Secondary data were obtained, obtained through the indicators of the Clinical Pharmacy Service, derived from routine activities of the clinical pharmacists. Resident intensive care pharmacists perform, daily (on average 3 days per week), an assessment of daily water balance, patient laboratory parameters and medical prescriptions (assessing dose, frequency, dosage, route of administration, drug interaction, dilution, and compatibility, among others). After this evaluation, suggestions for pertinent interventions are made during the patient's bed visit and the preparation of the medical prescription (digitized and two-way), suggesting to the prescriber possible changes to be made to ensure the safe and rational use of drugs.
The interventions suggested by the intensive care resident pharmacists are recorded in a database formed from specific Excel spreadsheets. This database is fed with the date of the intervention, the patient's medical record number, the prescribed form of the drug before and after the intervention, whether such an intervention was accepted, cost savings, intervention savings and classification, where each type of intervention receives an identification number and is grouped according to pre-established criteria in an already established indicator.

Secondary data were used, obtained through clinical pharmacy service indicators, producing variables.

The variables studied were the following: interventions (percentage of interventions accepted; number of total and ICU interventions; percentage and main interventions that generated cost savings), types of interventions/ categorization of interventions (change of pharmaceutical form; change of pharmaceutical formula; increase drug dose reduction, drug dose reduction, change of administration time by drug/nutrient interaction or other reason, request for examination for drug therapy monitoring, intervention with the nursing team about techniques and administration time, suggestion to include of drug in the patient's prescription, alert about the presence of adverse drug reaction, alert about the possibility of relevant drug interaction, recommendation for withdrawal of the drug from the prescription, drug dose calculation with the medical team, drug conciliation, dilution guidance or correction, supplemental dose inclusion guidance after dialysis, change of administration route, infusion time guidance or correction, prescription adequacy to hospital standardization, antimicrobial treatment time information according to $\mathrm{CCIH}$, others) and total value saved.

Included in the "others" category all interventions that were performed and do not fit the predefined categorization. Examples: communication to the medical team of results of previously requested tests, diet information, orientation on the next dose of drug, relevant changes in the patient's water balance (absence of bowel movement, diarrhea, fever, absence of diuresis, vomiting).

The total amount saved was calculated according to the following formula:

Formula: Sum of all value saved with cost saving.

\section{Cost saving $=[\mathrm{CDTxFAbxTD}]-[\mathrm{CDTxFAaxTD}]$, where}

\section{CDT: mean cost of drug therapy.}

FAb: frequency of administration/day before intervention.

TD: duration of treatment after intervention.

FAa: frequency of administration/day after intervention.

The value saved per day from the change in drug therapy was extrapolated to the total expected treatment duration, thus generating the total saved per intervention.

\section{Data analysis}

A descriptive analysis of the data was performed by calculating frequency, percentage and position measurements (mean and standard deviation), expressed as proportions (relative frequency) and presented as tables. The analyses were performed in Excel $2013^{\circ}$.

\section{Ethical considerations}

This study was approved by the Ethics Committee - CAAE: 88016318.2.0000.5138

\section{Results}

During the study period, 958 patients were admitted and 664 were included in the study, as shown in Figure 1. Regarding the place of hospitalization, 380 were admitted to the ICU-PO (57\%) and 284 patients were admitted to the ICU-AC (43\%).

Regarding the acceptance of the Clinical Pharmacy Service, the suggested interventions were well accepted (99.6\%). In the ICU-AC, the number of interventions performed was higher in all months of the study when compared to the ICU-PO. 7,781 interventions were performed, of which 7,747 were accepted. The main interventions performed were drug inclusion, drug withdrawal, dose reduction, infusion time and dilution (Table 1). 
Figure 1: Inclusion flow of the patients on whom the Clinical Pharmacy Service performed the interventions.

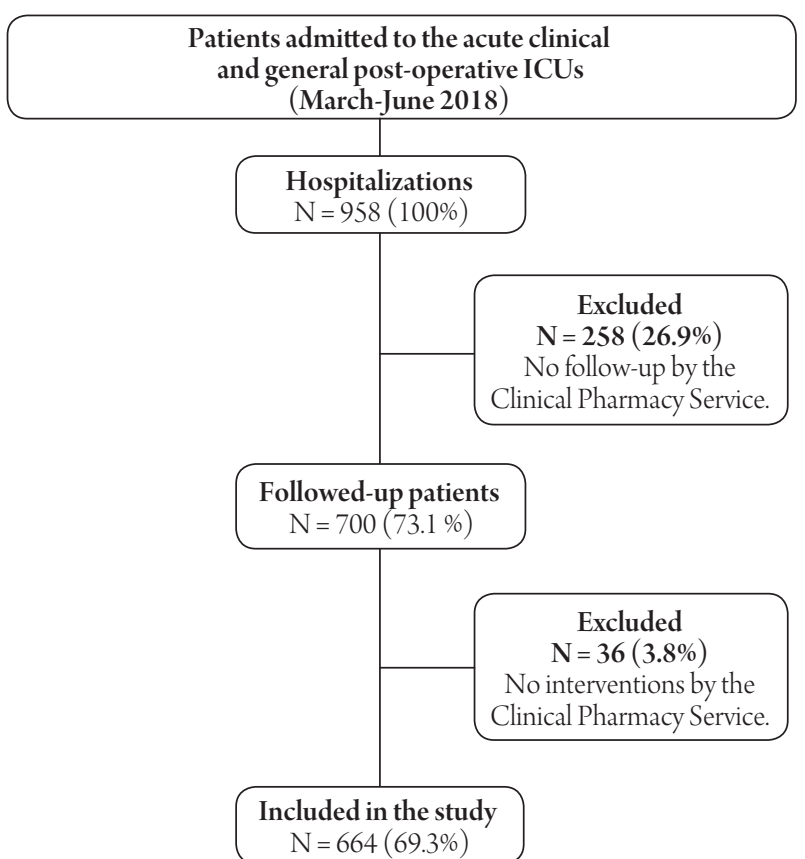

Of the accepted interventions, 1,934 (25.0\%) generated cost saving. The total saved with the interventions was $\mathrm{R} \$ 163,656.40$. The most frequent types of interventions related to cost saving were drug withdrawal (58.5\%), dose reduction (32.6\%), and change of pharmaceutical formula (3.0\%).

In the ICU-AC, the cost saving was greater in all months of the study $(\mathrm{R} \$ 27,939.30 \pm 6,474.33)$, when compared to the ICU-PO

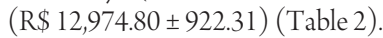

\section{Discussion}

The acceptance of the suggested interventions (99.6\%) demonstrates that the performance of the clinical pharmacist is already consolidated in the hospital where the study took place. A similar result was found by Leape et al. ${ }^{13}$, where the pharmacist made 366 drug order recommendations, of which 362 (99\%) were accepted by the medical team. On the other hand, other studies had a lower acceptance percentage than presented in this study. The acceptance of the pharmaceutical interventions in Klopotowska et al. ${ }^{3}$ study was $71 \%$, a result similar to that found by Reis et al. ${ }^{12}: 74.71 \%$ of acceptance. In the ICU-AC, the number of interventions performed was higher in all months of the study. It is inferred that in ICU-AC, the patients use a larger number of drugs, especially antimicrobials, when compared to the patients admitted to the ICU-PO, being more susceptible to prescribing errors and consequently to pharmaceutical interventions.

The main interventions performed were drug inclusion, drug withdrawal, dose reduction, infusion time and dilution. Despite the difficulty in comparing studies due to different categorizations and lack of standardization, other studies presented results similar to ours. There is a higher percentage of interventions related to drug inclusion (28.2\%) and dose review $(25.8 \%)$ in a study by Bourne and Choo 14. Drug suspension accounted for $18.97 \%$ and $17.9 \%$ of the interventions by Reis et al..$^{12}$ and Bourne and Chool4respectively. Errors in the omission of drugs or doses corresponded to $31.6 \%$ and inadequate dosing errors corresponded to $18.5 \%$ of the interventions performed by Klopotowska et al. ${ }^{3}$.

Of the interventions accepted, 1,934 (25\%) generated cost savings. The result of our study is superior to that found by Kopp et al. ${ }^{15}$, where $12(9.0 \%)$ of the interventions generated cost saving. There were no national studies evaluating the cost saving resulting from the pharmaceutical participation in the multidisciplinary intensive care team. In the study by Montazeri and Cook ${ }^{16}, 121$ (47.1\%) of the interventions performed generated cost saving.
Table 1. Interventions performed by the pharmacist in the $\mathrm{AC}$ and $\mathrm{PO}$ ICUs. Belo Horizonte, March-June 2018.

\begin{tabular}{|c|c|c|c|}
\hline Information & $\begin{array}{c}\text { Total } \\
\mathrm{N}=7,781\end{array}$ & $\begin{array}{l}\text { ICU-AC } \\
\mathrm{N}=4,876\end{array}$ & $\begin{array}{l}\text { ICU-PO } \\
\mathrm{N}=2,905\end{array}$ \\
\hline \multicolumn{4}{|l|}{ Interventions performed $\mathrm{n}(\%)$} \\
\hline March & $1,948(25.0)$ & $1,209(62.1)$ & $739(37.9)$ \\
\hline April & $1,972(25.3)$ & $1,173(59.5)$ & $799(40.5)$ \\
\hline May & $2,011(25.8)$ & $1,392(69.2)$ & $619(30.8)$ \\
\hline June & $1,850(23.8)$ & $1,102(59.6)$ & $748(40.4)$ \\
\hline \multicolumn{4}{|l|}{ Interventions accepted n (\%) } \\
\hline March & $1,935(24.9)$ & 1,199(99.2) & $736(99.6)$ \\
\hline April & $1,968(25.3)$ & $1,169(99.7)$ & $799(100.0)$ \\
\hline May & $2,008(25.8)$ & $1,389(99.8)$ & $619(100.0)$ \\
\hline June & $1,836(23.6)$ & $1,102(100.0)$ & $734(98.1)$ \\
\hline Total & $7,747(99.6)$ & $4,859(99.6)$ & $2,888(99.4)$ \\
\hline \multicolumn{4}{|l|}{ Types of interventions n (\%) } \\
\hline Drug inclusion & $1,276(16.5)$ & $831(17.1)$ & $445(15.4)$ \\
\hline Drug withdrawal & $1,275(16.5)$ & $908(18.7)$ & $367(12.7)$ \\
\hline Dose reduction & $698(9.0)$ & $476(9.8)$ & $222(7.7)$ \\
\hline $\begin{array}{l}\text { Guidance or correction of } \\
\text { infusion time }\end{array}$ & $589(7.6)$ & $357(7.3)$ & $232(8.0)$ \\
\hline $\begin{array}{l}\text { Dilution orientation or } \\
\text { correction }\end{array}$ & $479(6.2)$ & $277(5.7)$ & $202(7.0)$ \\
\hline $\begin{array}{l}\text { Antimicrobial Time - Hospital } \\
\text { Infection Control Commission }\end{array}$ & $458(5.9)$ & $380(7.8)$ & $78(2.7)$ \\
\hline Dose increase & $188(2.4)$ & $132(2.7)$ & $56(1.9)$ \\
\hline $\begin{array}{l}\text { Drug dose calculation with the } \\
\text { medical team }\end{array}$ & $184(2.4)$ & $145(3.0)$ & $39(1.4)$ \\
\hline $\begin{array}{l}\text { Change of route of } \\
\text { administration }\end{array}$ & $124(1.6)$ & $59(1.2)$ & $65(2.3)$ \\
\hline $\begin{array}{l}\text { Adequacy of prescription to } \\
\text { hospital standardization }\end{array}$ & $113(1.5)$ & $93(1.9)$ & $20(0.7)$ \\
\hline Pharmaceutical formula change & $105(1.4)$ & $41(0.8)$ & $64(2.2)$ \\
\hline Drug conciliation & $84(1.1)$ & $9(0.2)$ & $75(2.6)$ \\
\hline $\begin{array}{l}\text { Intervention with the nursing } \\
\text { staff on techniques and } \\
\text { administration time }\end{array}$ & $80(1.0)$ & $56(1.2)$ & $24(0.8)$ \\
\hline $\begin{array}{l}\text { Change of administration time } \\
\text { by drug/nutrient interaction or } \\
\text { other reason }\end{array}$ & $52(0.7)$ & $20(0.4)$ & $32(1.1)$ \\
\hline $\begin{array}{l}\text { Supplementary dose inclusion } \\
\text { guidance after dialysis }\end{array}$ & $46(0.6)$ & $33(0.7)$ & $13(0.5)$ \\
\hline Pharmaceutical form change & $36(0.5)$ & $33(0.7)$ & $3(0.1)$ \\
\hline $\begin{array}{l}\text { Warning of adverse drug } \\
\text { reaction }\end{array}$ & $11(0.1)$ & $10(0.2)$ & $1(0.0)$ \\
\hline $\begin{array}{l}\text { Examination request for drug } \\
\text { therapy monitoring }\end{array}$ & $9(0.1)$ & $2(0.0)$ & $7(0.2)$ \\
\hline $\begin{array}{l}\text { Warning about the possibility } \\
\text { of a relevant drug interaction }\end{array}$ & $8(0.1)$ & $4(0.1)$ & $4(0.1)$ \\
\hline Others & $1,932(24.9)$ & $993(20.4)$ & $939(32.5)$ \\
\hline
\end{tabular}


Table 2. Total Cost saving and per ICU grouped monthly. Belo Horizonte, March-June 2018.

\begin{tabular}{|c|c|c|c|}
\hline Information & $\begin{array}{c}\text { Total } \\
\mathrm{N}=7,781\end{array}$ & $\begin{array}{l}\text { ICU-AC } \\
\mathrm{N}=4,876\end{array}$ & $\begin{array}{l}\text { ICU-PO } \\
\mathrm{N}=2,905\end{array}$ \\
\hline \multicolumn{4}{|l|}{ Interventions n (\%) } \\
\hline Accepted & $7,747(99.6)$ & $4,859(62.7)$ & $2,888(37.3)$ \\
\hline Not accepted & $34(0.4)$ & $17(0.2)$ & $17(0.2)$ \\
\hline Mean cost saving & $1,934(25)$ & $1,307(16.9)$ & $627(8.1)$ \\
\hline \multicolumn{4}{|c|}{ Mean monthly cost saving $(\mathrm{R} \$$ ) } \\
\hline March & $35,328.91$ & $21,757.93$ & $13,570.98$ \\
\hline April & $50,669.64$ & $37,053.99$ & $13,615.65$ \\
\hline May & $37,830.10$ & $26,188.21$ & $11,641.89$ \\
\hline June & $39,827.75$ & $26,757.07$ & $13,070.68$ \\
\hline Total saved & $163,656.40$ & $111,757.20$ & $51,899.20$ \\
\hline
\end{tabular}

The total saved was $\mathrm{R} \$ 163,656.40$ and the most frequent types of interventions related to cost saving were the following: drug withdrawal (58.5\%), dose reduction (32.6\%), and change of pharmaceutical formula (3.0\%). Considering that the study was conducted in a hospital certified as a Charitable Organization of Social Assistance that exclusively serves SUS patients, the savings obtained through the reduction of pharmaceutical intervention costs becomes even more relevant. In the study by Saokaew, Maphanta and Thangsomboon ${ }^{17}$, the most common types of interventions related to cost saving were providing the required written order information (25.98\%), staff request for information (e.g., drug storage and compatibility) (21.26\%), and dose adjustment by renal function (15.75\%).

In the study by Saokaew, Maphanta \& Thangsomboon ${ }^{17}$, savings were calculated similarly to our study, and the pharmacist interventions yielded a total of USD 1,971.43 in drug cost savings over a 5-week period. In the study by Kopp et al. ${ }^{15}$, six of the interventions resulted in a cost savings of USD 10 to USD 100, three resulted in a cost savings of USD 101 to USD 1,000, and three of the interventions resulted in a cost savings of more than USD 1,000.

Although it is difficult to directly compare with other studies due to different methodologies adopted and currencies used, a significant cost saving resulting from the pharmaceutical intervention is generally perceived. According to Klopotowska et al. ${ }^{3}$, there is a 9 to 13 fold financial return when a hospital pharmacist is implanted in the ICU. The results of a study by Kopp et al. ${ }^{15}$ demonstrated that the potential cost avoidance for 129 documented interventions over a 4.5-month period was USD 205,919 - USD 280,421. In addition, most of the avoided costs were generated from interventions made during the pharmacist's participation in clinical rounds and chart review.

In the ICU-AC, the cost saving was greater in all months of the study. It assumes that in ICU-AC, interventions related to cost saving are more frequent than in the ICU-PO. Another justification would be the much higher number of interventions in the ICU-AC, which increases the chance of interventions related to cost saving.

Regarding the contributions of this work to the hospital where the study took place, there is a relevant contribution of the clinical pharmacist in relation to patient safety in the safe drug item. The interventions performed are directly related to the assessment of need (drug inclusion/withdrawal), effectiveness (interventions based on the patient's clinical response) and safety (drug dose-related interventions, minimization of predictable ADRs and reduction of drug interactions which compromise the clinical course), triad based on the rational use of drugs.

Considering that the institutional clinical protocols were part of the references used by the pharmacists for decision making, there is a contribution to improve the adherence of these protocols in the units with the participation of the clinical pharmacist

Knowing that in the ICU-AC the number of interventions and the cost saving were greater in all months of the study, it is suggested to prioritize the clinical pharmacist in this sector over the ICU-PO in case of a contingency plan due to embezzlement in the staff.

The cost saving resulting from the accepted interventions provides the distribution of the saved value in other areas of the hospital. Being even a substrate for hiring new pharmaceutical professionals aiming to expand the clinical pharmacy service developed, since the total saved monthly is enough to afford the hiring of new employees.

Regarding the limitations of this study, we can mention the design and the short follow-up period. The rationale for choosing the design was the difficulty in obtaining waiver of the Free and Informed Consent Form (FICF) in a prospective study in which, at the time of data collection, the participants would be hospitalized. Considering that many ICU patients have a substantial decrease in their consent capacities, it would be up to the legal guardians to sign the consent form. Because the researcher and four ICUs had similar visiting hours, choosing a prospective study would directly impact the reduction in the sample size. Therefore, we opted for a cross-sectional observational study, using only information from indicators of the Clinical Pharmacy Service, in which at the time of data collection the participants would not be hospitalized, a FICF waiver being requested.

Regarding the study time, it was sufficient to demonstrate the impacts of the clinical pharmacist's work in the ICU. However, studies with a longer evaluation time would be interesting to determine if outcome measures would be influenced by a learning process over time ${ }^{2}$.

It is hoped with this work to reinforce the importance of the pharmacist's performance in ICUs and to spread the pharmacotherapeutic follow-up during the multidisciplinary bed run as one of the strategies to promote patient safety in drug use.

\section{Conclusion}

In our study, the performance of the clinical pharmacist in intensive care units was well accepted by the medical team. There are several possibilities for interventions that contribute to the rational use of drugs, ensuring that they receive the necessary medicine at the appropriate dose and at the lowest cost. Some pharmaceutical interventions have a direct impact on cost saving, and further studies are needed to quantify the savings generated from these interventions.

In addition to being one of the strategies to promote patient safety in the use of drugs, the pharmacotherapeutic follow-up during the multidisciplinary visit to the patient's bed has institutional benefits such as quality improvement and reduction of health care costs. This follow-up has relevance in public health because it ensures the safe use of drugs and brings savings in the pharmaceutical care provided by the Public Healthcare System (Sistema Único de Saúde, SUS). Therefore, it can be concluded that it should be implemented in other Brazilian institutions.

\section{Funding sources}

The authors did not receive any funding for the study.

\section{Authors' Contribution}

ECSM participated in all stages of the work (project conception and data analysis and interpretation; writing of the article and relevant critical review of the intellectual content and final approval of the version to be published). ASBP and $\mathrm{RPB}$ conducted a relevant critical review of the intellectual content and the final approval of the version to be published. All authors have responsibility for all the information of the work, ensuring accuracy and integrity of any of its parts.

\section{Conflict of interests}

The authors declare no conflicts of interest.

\section{Acknowledgments}

We thank the institutional support of the hospital where the study took place.

\section{References}

1. Anacleto TA, Rosa MB, Neiva HM, et al. Farmácia hospitalar: erros de medicação. Farmácia Hospitalar-Farmacovigilância hospitalar: como implantar, p. 1-23, 2010. Disponível em: <http://www.cff.org.br/sistemas/geral/revista/ pdf/124/ encarte_farmaciahospitalar.pdf $>$. Accessed: 31 mar. 2018. 
2. World Health Organization. WHO launches global effort to halve medication-related errors in 5 years. Geneva: World Health Organization, 2017. Accessed: 31 mar. 2018

3. Klopotowska, J.E. et al. On-ward participation of a hospital pharmacist in a Dutch intensive care unit reduces prescribing errors and related patient harm: an intervention study. Critical Care, 2010;14(5):174.

4. Patel, G.P.; Kane-Gill, S.L. Medication error analysis: a systematic approach Current drug safety. 2010;5(1):2-5.

5. Barber, N, Rawlins, M, Dean Franklin, B. Reducing prescribing error:competence, control, and culture. Qual Saf Health Care. 2003;12(1):29-32.

6. Kane-Gill S, Rea RS, Verrico MM, et al. Adverse-drug-event rates for high-cost and high-use drugs in the intensive care unit. American journal of health-system pharmacy. 2006;63(19):1876-1881.

7. Kane-Gill S, Rea RS, Verrico MM, et al. Adverse-drug-event rates for high-cost and high-use drugs in the intensive care unit. American journal of health-system pharmacy. 2006;63(19):1876-1881.

8. Weber, R. J. et al. Impact of intensive care unit (ICU) drug use on hospital costs: a descriptive analysis, with recommendations for optimizing ICU pharmacotherapy. Critical care medicine. 2003;31(1):S17-S24

9. Brasil. Ministério da Saúde. Secretaria de Ciência, Tecnologia e Insumos Estratégicos. Uso racional de medicamentos: temas selecionados / Ministério da Saúde, Secretaria de Ciência, Tecnologia e Insumos Estratégicos Brasília: Ministério da Saúde, 2012.

10. Ferracini FT, Almeida SM, Locatelli J, et al. Implementation and progress of clinical pharmacy in the rational medication use in a large tertiary hospital. Einstein. 2011;9(4):456-460.

11. Pilau R, Hegele V, Heineck L. Atuação do farmacêutico clínico em unidade de terapia intensiva adulto: uma revisão da literatura. Rev Bras Farm Hosp Serv Saúde. 2014;5(1):19-24

12. Reis WCT, Scopel CT, Correr CJ, et al. Análise das intervenções de farmacêuticos clínicos em um hospital de ensino terciário do Brasil. Einstein. 2013;11(2):190-196

13. Leape, L.L. et al. Pharmacist participation on physician rounds and adverse drug events in the intensive care unit. Jama. 1999;282(3):267-270.

14. Bourne RS, Choo CL. Pharmacist proactive medication recommendations using electronic documentation in a UK general critical care unit. International Journal of Clinical Pharmacy. 2012:34:351-357.

15. Kopp, B.J. et al. Cost implications of and potential adverse events prevented by interventions of a critical care pharmacist. American Journal of Health-System Pharmacy. 2007;6(423):2483-2487.

16. Montazeri M, Cook DJ. Impact of a clinical pharmacist in a multidisciplinar intensive care unit. Critical care medicine. 1994:22(6):1044-1048.

17. Saokaew S, Maphanta S, Thangsomboon P. Impact of pharmacists interventions on cost of drug therapy in intensive care unit. Pharmacy practice. 2009; $7(2): 81$. 